\title{
6/6 HLA Match
}

National Cancer Institute

\section{Source}

National Cancer Institute. 6/6 HLA Match. NCI Thesaurus. Code C158478.

Complete HLA matching for HLA-A, -B and -DRB1 loci. 